\title{
Combination of adaptive median filter with ACO for eliminating the impulsive noise from colour images
}

\author{
Rahul Malhi ${ }^{*}$, P.S. Maan ${ }^{2}$ \\ ${ }^{1 *}$ Research Scholar,Computer Science \& Engineering, DAVIET, PTU, Jalandhar, Punjab, India \\ ${ }^{2}$ Assistant Professor,Computer Science \& Engineering, DAVIET, PTU, Jalandhar, Punjab, India \\ e-mail: rahulmalhi07@gmail.com,psmaan@hotmail.com
}

\begin{abstract}
In this research paper, we proposed an ACO with a versatile for vector middle channel for the expulsion of motivation commotion from shading pictures. Regularly, the homogeneousness among the pixels is adulterated, when motivation clamor extraordinarily contorted the pictures. In the proposed method, just when the sifting activity will be done if the pixel is observed to be ruined. The choice about a specific pixel of being undermined or not relies upon the straight forecast blunder figured from the non-causal locale around the pixel under operation. Versatile window based vector middle separating activity will be done, if the mistake of the center pixel of the bit outperforms the officially characterized limit esteem. The span of versatile window will rely upon the level of blunder as indicated by the effectively characterized limit esteem. The proposed sifting system in charge of enhancing the pinnacle flag to clamor proportion (PSNR).
\end{abstract}

Keywords - Impulse noise; vector median filter; adaptive filtering;similarity index measure.

\section{INTRODUCTION}

Image rebuilding is dependable to reestablish the debased picture into genuine picture. Certain purpose of corruption and mutilation are unavoidable in the arrangement, transmission, stockpiling, recording and show of the picture. Since image quality debasement might be caused in each connection of the development of computerized image, by and large, the image should be reestablished keeping in mind the end goal to get amazing advanced image [2].

Images are produced to catch the valuable data. In any case, because of numerous flaws in the catching frameworks, the caught pictures are in the long run spoken to a debased show of the real scene. There are many explanations behind the corruption, however the two sorts of debasements that are regularly overwhelming to commotion and obscuring.

\section{IMPULSIVE NOISE MODEL}

There are two sorts of drive commotion: arbitrary esteemed motivation clamor and settled esteemed motivation commotion. The settled driving forces demonstrate is additionally called the "salt and pepper commotion display".

Vol 1 (3) September 2017, www.ijirase.com
At the point when motivation commotion have vast esteem (255), it is named as the 'salt' clamor and if then commotion is having little esteem (0) it is named as the 'pepper' commotion. On the off chance that ' $p_{l}$ ' demonstrates the likelihood of event of low esteemed drive commotion in a flag part and that ' $p_{2}$ ' gives the likelihood of event of a high esteemed motivation clamor in a similar flag, at that point the aggregate likelihood of event of 'salt and pepper commotion' in the flag under thought is given by $\left(p_{1}+p_{2}\right)$. On the off chance that 256 (one pixel in a dim channel is spoken to utilizing 8 bit) is the quantity of dim levels utilized per pixel, at that point we expect that 255 or ' $h$ ' speaks to the 'salt commotion, while 0 or ' $l$ ' speaks to the 'pepper' clamor. Let $X_{c}$, (where $\mathrm{c}=1$ for red, 2 for green or 3 for blue) be a pixel part of a vector pixel in any of the channels of a multichannel image.

model:

The impulse noise is expressed through following

$$
X_{c}=\left\{\begin{array}{l}
l, \text { with probability } p 1 \\
h, \text { with probabilty } p 2 \\
S_{c}, \text { with probability } p 3
\end{array}\right.
$$

\section{Methodology}

For the expulsion of motivation clamor of all thickness of drive commotions, ACO based non-causal straight expectation versatile middle channel has been proposed in this paper.

This proposed procedure dependable to take pixels around the non-causal neighboring locale for figuring gauge mistake. The coefficients are computed by utilizing a model named, Autoregressive Moving Average Model (ARMA).

In the versatile middle channel with ACO procedure, the window measure is nearly novel according to the assessed blunder while the separating operation. The proposed method performs denoising process on all the debased pictures from the "drive commotion". 


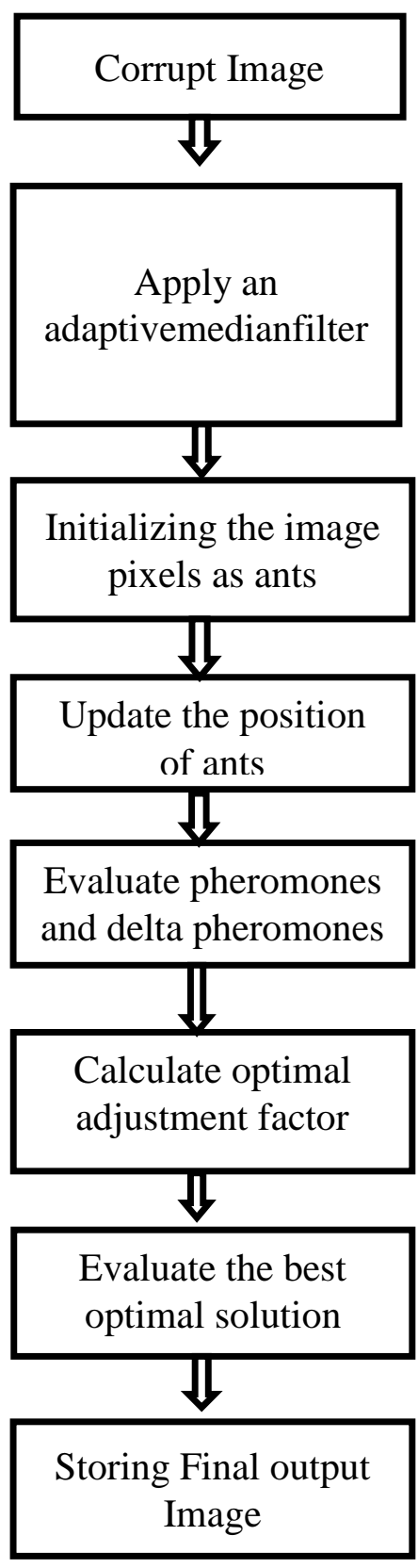

Fig.1. Shows the methodology of proposed method

\section{IV.RESULTS AND DISCUSSION}

The examinations have been done on number of pictures with various densities of commotions. The execution of the framework is ascertained by execution measure, PSNR. The investigation has been done as far as two sided settled esteemed motivation clamor. Standard shading pictures like Lena, Mandrill, Tulip, Pepper, and Cameraman are a portion of the pictures utilized as a part of this investigation. Amid the procedure of experimentations, the misleadingly drive clamors are included into previously mentioned pictures and the exhibitions are surveyed by the PSNR execution metric.

The PSNR execution parameter is measured as far as $\mathrm{dB}$ unit. The PSNR for shading pictures is said underneath::

$$
P S N R=10 \log _{10}\left(\frac{l_{M A X}^{2}}{M S E}\right)
$$

Where, $I_{M A X}$ indicates the greatest estimation of the vector pixel of the genuine picture.

Amid the investigation of execution examination, the proposed system has been contrasted and a versatile noncausal direct forecast based vector middle channel (ANCLPVMF) [20].

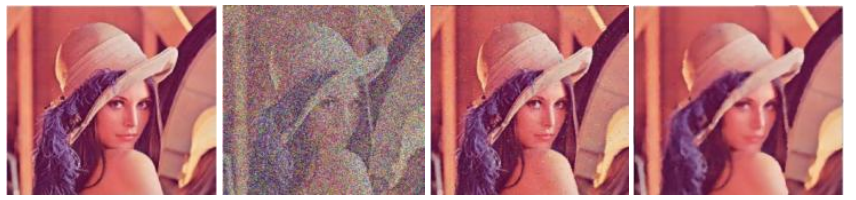

Fig. 2.(a) Actualimage 1 (Lena), (b) Image contained 30\% of addictive impulse noise, (c) Image filtered by ANCLPVMF, (d) Image filtered PROPOSED technique.
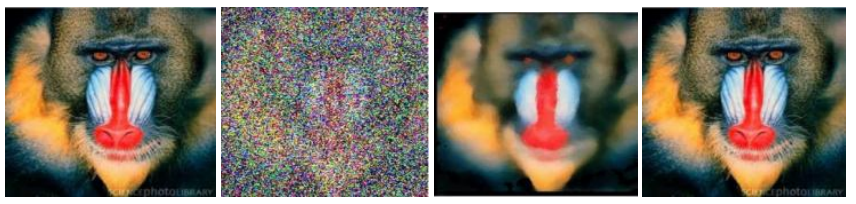

Fig. 3. (a) Actualimage 2 (Mandrill), (b) Image contained $30 \%$ of addictive impulse noise, (c) Image filtered by ANCLPVMF, (d) Image filtered PROPOSED technique.
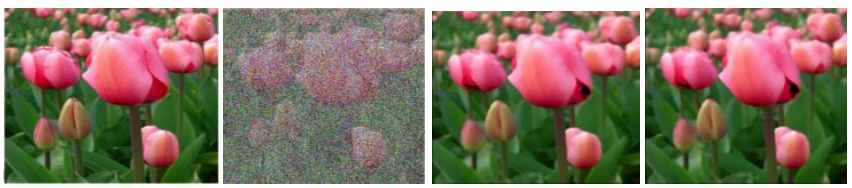

Fig. 4. (a) Actual image 3 (Tulip), (b) Image contained 30\% of addictive impulse noise, (c) Image filtered by ANCLPVMF, (d) Image filtered PROPOSED technique.

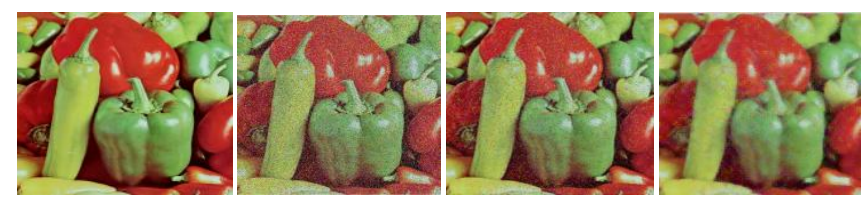


Fig. 5. (a) Actualimage 4 (Pepper), (b) Image contained 30\% of addictive impulse noise, (c) Image filtered by ANCLPVMF, (d) Image filtered PROPOSED technique.
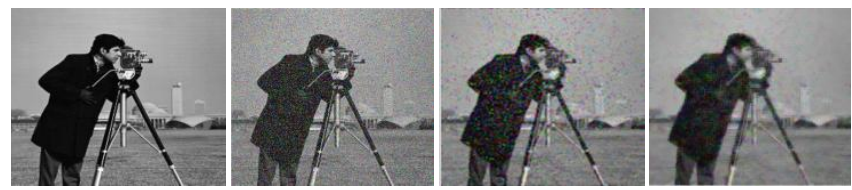

Fig. 6. (a) Actual image 5 (Cameraman),Image contained $30 \%$ of addictive impulse noise, (c) Image filtered by ANCLPVMF, (d) Image filtered PROPOSED technique.

From above Figures, number of pictures has been appeared for proposed method while drive commotion has been misleadingly added to the real pictures. It is inferred that the high thickness drive commotion is expelled.

\section{A. Performance evaluations for Impulse Noise}

Table 1 Performance evaluations show that the comparison between different methods on number of images degraded with 30\% impulse noise. The value of PSNR performance parameter in decibels $(\mathrm{dB})$ unit has been mentioned below.

\begin{tabular}{|l|l|l|}
\hline Images/Filters & ANCLPVMF & $\begin{array}{l}\text { PROPOSED } \\
\text { METHOD }\end{array}$ \\
\hline Image 1 & 25.27 & 35.41 \\
\hline Image 2 & 23.05 & 35.17 \\
\hline Image 3 & 28.28 & 35.51 \\
\hline Image 4 & 24.43 & 35.06 \\
\hline Image 5 & 23.08 & 35.78 \\
\hline
\end{tabular}

In Table 1, experiment has been carried out with different number of images. It is found that the proposed technique provides better performance for all images as shown above.

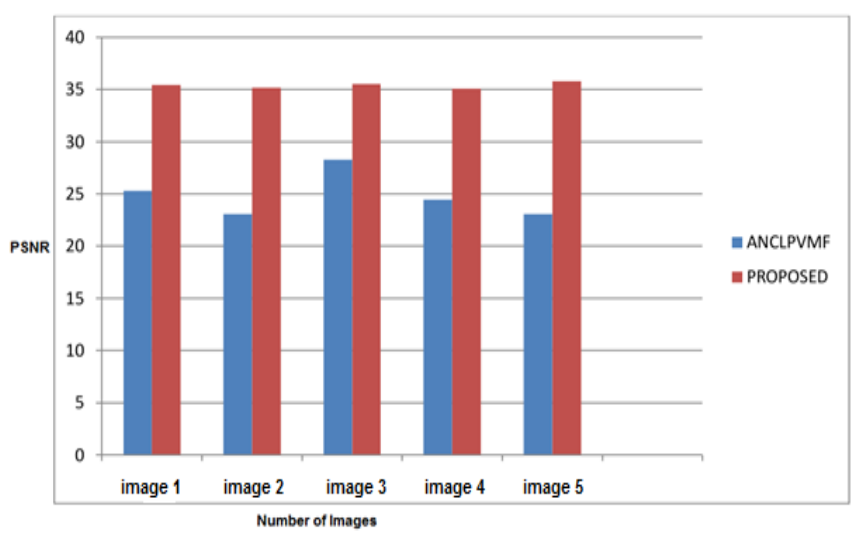

Fig.7. PSNR graph for no. of images

Table 2Execution assessment demonstrate that the Examination between the considered Channels in expelling the Drive Commotion from the picture debased with Motivation Clamor taking the parameter PSNR for hued picture. The estimation of PSNR execution parameter is measured as far as decibels $(\mathrm{dB})$ unit has been said beneath.

\begin{tabular}{|l|l|l|}
\hline Noise Percentage/Filters & ANCLPVMF & $\begin{array}{l}\text { PROPOSED } \\
\text { METHOD }\end{array}$ \\
\hline 10 & 32.59 & 36.86 \\
\hline 20 & 28.56 & 36.31 \\
\hline 30 & 25.27 & 35.41 \\
\hline 40 & 22.61 & 34.72 \\
\hline 50 & 20.47 & 34.15 \\
\hline 60 & 18.68 & 33.68 \\
\hline 70 & 17.20 & 33.42 \\
\hline
\end{tabular}

In Table 2, lists records the execution of the previously mentioned channels in expelling the motivation clamor from considered picture corrupted by drive commotion. The estimations of PSNR are noted when the picture is debased by commotion densities in the middle of $10 \%-70 \%$. For lower to higher clamor level of motivation commotion, the PROPOSED system overwhelms the ANCLPVMF. Consequently, the proposed system beats the ANCLPVMF.

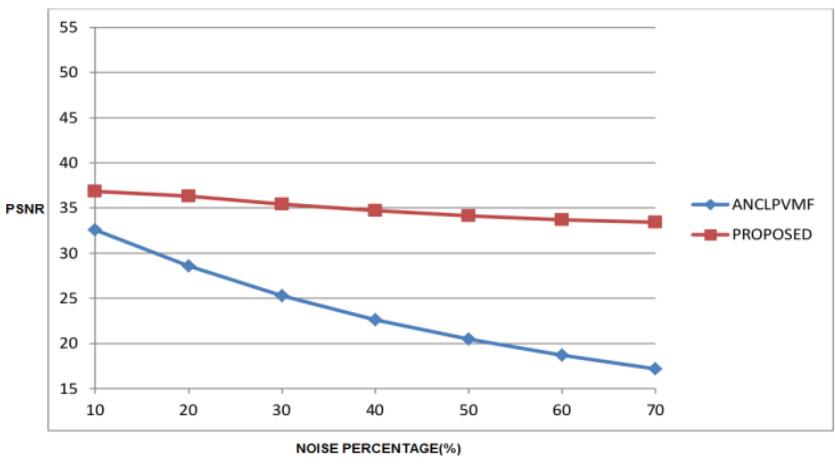

Fig.8. PSNR graph for no. of images

\section{CONCLUSION ANd Future SCOPE}

In this exploration paper, proposed an ACO based versatile middle separating strategy for the evacuation of drive clamor having high commotion rates from the shading pictures. The Subterranean insect State streamlining is a procedure which is utilized for picture preparing. As ACO is utilized for enhancement of nonstop issues, so it is utilized for different uses of picture preparing which indicates consistent conduct. The Subterranean insect Province streamlining gives the

Vol 1 (3) September 2017, www.ijirase.com 
ISSN(Online) : 2456-8910

International Journal of Innovative Research in Applied Sciences and Engineering (IJIRASE)

Volume 1, Issue 3, DOI: 10.29027/IJIRASE.v1.i3.2017.102-105, September 2017

ideal arrangements which are additionally handled to locate the genuine outcomes. It gives many yields on various edge esteems. The most brief way of ants has more pheromone than longest ways. So the pheromone refreshing data is essential in ACO. The execution assessment of the proposed technique is surveyed by utilizing target measure, for example, PSNR. The Test comes about with examination investigation demonstrate that proposed calculation beats a few other considered sifting systems.

The speculative outcomes inferred that the proposed strategy proficiently comes about into the evacuation of high thickness motivation commotion from an undermined picture with various clamor rate (densities from $10 \%$ to $70 \%$ ). Accordingly, the separated picture is denoised picture given by the proposed strategy.

As a future extent of work, existing system is done with restorative pictures. The examination may likewise be conveyed forward by considering the low thickness drive clamor for upgrading the execution of the framework.

\section{REFERENCES}

[1] K. Sakthidasan Sankaran , N. Velmurugan Nagappan, Noise free image restoration using hybrid filter with adaptive genetic algorithm, Computers and Electrical Engineering 000 (2016) 1-11.

[2] Zhang H, Yang J, Zhang Y, Huang T. Image and video restoration via non-local kernel regression. IEEE Trans Cybern 2013; 43(3):1035-46

[3] Lien C-Y, Huang C-C, Chen P-Y, Lin Y-F, An efficient denoising architecture for removal of impulse noise in images. IEEE Trans Computer 2013; 62(4):631-43.

[4] Zhao JF, Feng H-J, An improved image restoration approach using adaptive local constraint. Opt Int J Light Electron Opt 2012; 123(11):982-5

[5] R H Chan, H W Chung, M Nikolova, Salt-and-Pepper noise removal by median-type noise detectors and detailpreserving regularization, IEEE Transaction on Image Processing. 14(10) (2005) 1479-1485.

[6] ANNA VERONICA C. BATERINA, CARLOS $M$. OPPUS,"

[7] Ant Colony Optimization for Image Edge Detection" Department of Electronics and Communications Engineering Ateneo de Manila University Katipunan Avenue, Loyola Heights, , Quezon City Phillipines.

[8] Jing Tian, Weiyu Yu, Shengli Xie ," An Ant Colony Optimization Algorithm For Image Edge Detection", 2008 IEEE Congress on Evolutionary Computation (CEC 2008).

[9] C.Naga Raju, O.Rama Devi, Sharada Mani, Sanam Nagendram, "An Improved Ant Colony Optimization Technique by using Fuzzy Inference Rules for Image
Classification and Analysis", International Journal of Advanced Engineering \& Application, Jan. 2010

[10] Alirezae Rezaee," Extracting Edge of Images with Ant Colony "Journal of ELECTRICAL ENGINEERING, VOL. 59, NO. 1, 2008, pp. 57-59.

[11] Shahab Kamali, Jaroslav Opatrny, "A Position Based Ant Colony Routing Algorithm for Mobile Ad-hoc Networks", JOURNAL OF NETWORKS, VOL. 3, NO. 4, APRIL 2008.

[12] M. Dorigo, G. D. Caro, L. M. Gambardella., "Ant algorithms for discrete optimization.Artificial Life", 5(2): pp. 137-172, 1999.

[13] J. Dr'eo, P. Siarry., "Continuous interacting ant colony algorithm based on dense heterarchy". Future Generation Computer Systems, 20(5): pp. 841-856, June 2004.

[14] C.T. Lu, T.C. Chou, Denoising of salt-and-pepper noise corrupted image usingmodified directionalweighted-median filter, Pattern Recognit. Lett. 33 (2012)1287-1295.

[15] J. Wu, C. Tang, An efficient decision-based and edge-preserving method forsalt-and-pepper noise removal, Pattern Recognit. Lett. 32 (2011) 19741981. 